\title{
Inflammatory Cytokine Profiles of Semen Influence Cytokine Responses of Cervicovaginal Epithelial Cells
}

\begin{abstract}
Cosnet L. Rametse ${ }^{1}$, Anthonio O. Adefuye ${ }^{1,2}$, Abraham J. Olivier ${ }^{1}$, Lyle Curry ${ }^{1}$, Hoyam Gamieldien ${ }^{1,3}$, Wendy A. Burgers ${ }^{1}$, David A. Lewis ${ }^{4,5,6}$, Anna-Lise Williamson ${ }^{1,7}$, Arieh A. Katz ${ }^{1,7 \dagger}$ and Jo-Ann S. Passmore ${ }^{1,6,7 * t}$

${ }^{1}$ Institute of Infectious Diseases and Molecular Medicine, University of Cape Town, Cape Town, South Africa, ${ }^{2}$ University of the Free State, Bloemfontein, South Africa, ${ }^{3}$ NRF-DST CAPRISA Centre of Excellence in HIV Prevention, Cape Town, South Africa, ${ }^{4}$ Western Sydney Sexual Health Centre, Western Sydney Local Health District, Parramatta, NSW, Australia, ${ }^{5}$ Marie Bashir Institute for Infectious Diseases and Biosecurity, Sydney Medical School-Westmead, University of Sydney, Sydney, NSW, Australia, ${ }^{6}$ National Health Laboratory Services, Johannesburg, South Africa, ${ }^{7}$ SAMRC-UCT Gynaecological Cancer Research Centre, University of Cape Town, Cape Town, South Africa
\end{abstract}

Genital inflammatory cytokine responses increase HIV risk. Since male partner semen is a complex mixture of immune-modulatory prostaglandins and cytokines, we hypothesized that exposure to semen may influence genital inflammation in women. Here, we investigated cytokine response kinetics of cervical cells following stimulation with seminal plasma from HIV-negative and HIV-positive men characterized as having low or high concentrations of inflammatory cytokines. Irrespective of the HIV status or semen cytokine profile, in vitro stimulation of cervical cells with seminal plasma resulted in significantly elevated concentrations of secreted IL-6, IL-8, TNF- $\beta$, MCP-1, GM-CSF, and VEGF within $8 \mathrm{~h}$ of stimulation, which tended to decline by $24 \mathrm{~h}$, although this was only significant for TNF- $\beta$. Consistent with this, cervical cells responded to seminal plasma with increases in IL-8 and IL-1 $\beta$ mRNA expression of 10 -fold. These findings suggest that the impact of semen on local female genital cytokines is likely transient. Although these findings suggest that the impact of semen on local female genital cytokines may not be sustained long-term, this heightened genital inflammation may have implications for HIV risk in women.

Keywords: genital inflammation, HIV, semen, cytokines, HeLa, interleukins

\section{INTRODUCTION}

Semen is a complex fluid that ensures safe delivery of male genetic material into the female reproductive tract to ensure fertilization (1). In addition to $\sim 15$ million spermatozoa per milliliter of ejaculate, semen is a highly immune-modulatory mixture containing prostaglandin-E2 (PGE2), anti- and pro-inflammatory cytokines [including transforming growth factor (TGF) $-\beta$, interleukin (IL)-10, IL-8, macrophage colony stimulating factor (MCP)-1; regulated upon activation normal T cell expressed and secreted (RANTES), and secretory leukocyte protease (SLP)-1], all with the potential to alter the immune environment of the lower female reproductive tract (2-4). In addition to cytokines, seminal plasma also contains signaling molecules that induce expression of IL-1 $\beta$, IL-6, and leukemia inhibitory factor (LIF) by endometrial epithelial cells $(5,6)$, which triggers recruitment and activation of macrophages, dendritic cells (DC) and neutrophils (6-10). 
We have previously shown that $>70 \%$ of HIV positive men had detectable HIV in their semen (3). The concentrations of inflammatory cytokines were generally similar in seminal plasma from HIV-positive and -negative men (3). In women, unprotected sex is associated with increased ectocervical macrophages, DCs and $\mathrm{CD}^{+}{ }^{+}$T-cells, and decreased $\mathrm{CD} 4^{+}$ $\mathrm{T}$ cells within $12 \mathrm{~h}$ following intercourse (6). Shortly after unprotected sex, TGF- $\beta$ and vaginal $\mathrm{pH}$ were shown to be significantly elevated, while IL- 8 and human beta defensin (HBD)-3 concentrations were lower $(6,10)$. These changes in cytokine responses in women were transient, however, with levels normalizing within $14 \mathrm{~h}$. Similarly, ectocervical cell lines exposed to semen produced higher concentrations of IL-6, IL8 , IL- $1 \alpha$, and granulocyte macrophage colony stimulating factor (GM-CSF) (6).

Since inter-individual cytokine profiles of semen vary widely and according to HIV status (3), we investigated the temporal effects of seminal plasma from HIV-positive and -negative men with either high- or low cytokine profiles on in vitro cytokine responses by cervical epithelial cells.

\section{MATERIALS AND METHODS}

\section{Ethics Statement}

Ethic approval obtained from the University of Cape Town Human Research Ethics Committee. Written informed consent was obtained from all men before sample collection.

\section{Male Cohort Recruitment}

Thirty-eight HIV-positive and $28 \mathrm{HIV}$-negative men were enrolled from the Empilisweni Clinic in Athlone, South Africa (3). Ejaculates were collected in sterile specimen jars containing $6 \mathrm{ml}$ of transport media [RPMI-1640 medium supplemented with $5 \mathrm{mM}$ L-glutamine, $50 \mathrm{U} / \mathrm{ml}$ penicillin, $50 \mu \mathrm{g} / \mathrm{ml}$ streptomycin (GIBCO $^{\circledR}$, Invitrogen ${ }^{\mathrm{TM}}$, Carlsbad, CA, USA), $2 \mathrm{mg} / \mathrm{ml}$ fungin ${ }^{\circledR}$ (Invivogen, San Diego, CA, USA)] following voluntary selfmasturbation. In the laboratory, semen was centrifuged at 1,000 $\times \mathrm{g}$ for $10 \mathrm{~min}$ to remove cells and spermatozoa and seminal plasma was collected for subsequent experiments (3). All samples were processed in the laboratory within $2-4 \mathrm{~h}$ after donation and seminal plasma was stored at $-80^{\circ} \mathrm{C}$ for viral load determination and cytokine measurements.

\section{STI Testing}

A validated in-house real-time multiplex PCR assay was used to detect Neisseria gonorrhoeae, Chlamydia trachomatis, Trichomonas vaginalis, and Mycoplasma genitalium in DNA extracted from seminal plasma. DNA extraction was performed using the X-tractor gene platform (Qiagen, Germany) and MPCRs were performed using Rotor Gene 3000 platform (Corbett Research, Australia) as described previously (11). The primers and probes used in the multiplex assay targeted $N$. gonorrhoeae cytosine-specific DNA methyltransferase gene, C. trachomatis cryptic plasmid, the $T$. vaginalis repeated DNA fragment, and $M$. genitalium pdhD gene, encoding for dihydrolipoamide dehydrogenase (12). After incubation at $50^{\circ} \mathrm{C}(2 \mathrm{~min})$ and Taq activation at $95^{\circ} \mathrm{C}(10 \mathrm{~min}), 40$ cycles of denaturation $\left(95^{\circ} \mathrm{C}\right.$,
$20 \mathrm{~s})$, and annealing/extension $\left(60^{\circ} \mathrm{C}, 60 \mathrm{~s}\right)$ took place. Genomic DNA extracts prepared from the following ATCC strains served as controls: N. gonorrhoeae (ATCC 700825), C. trachomatis (ATCC VR-885), T. vaginalis (ATCC 30001), and M. genitalium (ATCC 33530). Specimens that were positive for C. trachomatis were further tested for lymphogranuloma venereumassociated L1-3 serovars (12).

\section{Measurement of HIV Concentrations in Plasma and Semen}

Plasma and seminal HIV-1 RNA concentrations (copies/milliliter) were quantified using NucliSENS EasyQ HIV-1 (version 2.0, bioMérieux SA, Lyon, France) according to the manufacturer's protocol. The assay had a lower limit of detection of 70 copies of HIV-1 RNA/mL and a linear range of detection up to $10 \times 10^{6}$ copies of HIV-1 RNA/mL.

\section{Measurement of Cytokines in Seminal Plasma}

The concentrations of 26 cytokines [including IL-1 $\beta$, IL-2, IL-6, IL-7, IL-12p70, GM-CSF, IFN- $\gamma$, TNF- $\alpha$, IL-1 $\alpha$, IL-8, IL-12p40, IL-15, eotaxin, fractalkine 3, G-CSF, MCP-1, MIP$1 \alpha$, and $-1 \beta$, RANTES, ITAC, monokine-induced by interferon Gamma (MIG), MIP-3 $\alpha$ and TGF- $\beta 1, \beta 2$ and $\beta 3$ ] were measured in semen using a human cytokine milliplex MAP kit (Millipore Corporation, St. Charles, Missouri, USA), according to the manufacturer's protocol. Seminal plasma samples were thawed and filtered by centrifugation using $0.2 \mu \mathrm{m}$ cellulose acetate filters (Sigma, USA) prior to cytokine/chemokine measurements, to exclude debris (3). All values below the detection limit were recorded as half of the lowest measured concentration for each cytokine.

\section{HeLa Cell Culture and Stimulation}

HeLa S3 cervical cells were cultured in Dulbeccos modified Eagles medium nutrient mixture F-12 (DMEM) with Glutamax1 enriched with $10 \%$ FCS (Highveld Laboratories, Cape Town, S.A), including Penicillin (1,533 IU/mg) and Streptomycin (775 $\mathrm{IU} / \mu \mathrm{g})$ at $37^{\circ} \mathrm{C}$ and $5 \% \mathrm{CO}_{2}(\mathrm{v} / \mathrm{v})$. Cells were stimulated with a 1:50 dilution of seminal plasma in serum-free media for 8 and $24 \mathrm{~h}$ (13). Untreated cells were included as a negative control. HeLa cell supernatants were harvested for measurement of secreted cytokines while cells were harvested into $1 \mathrm{ml}$ TRIzol ${ }^{\circledR}$ reagent (Invitrogen, US) for mRNA extraction. All experiments were done in triplicate. Supernatants and cells were centrifuged and stored at $-80^{\circ} \mathrm{C}$ until further use.

\section{Measurement of Cytokine Responses by HeLa Cells}

Following exposure of HeLa cells to seminal plasma, the concentrations of IL- $1 \alpha$, IL- $1 \beta$, IL- 6 , IL-8, GRO, GM-CSF, VEGF, TNF- $\alpha$, IP-10, and MCP-1 were measured in HeLa cell culture supernatants using the human cytokine milliplex MAP kit (Millipore Corporation, St. Charles, Missouri, USA), according to the manufacturer's protocol, as described previously (3). HeLa culture supernatants were filtered by centrifugation using $0.2 \mu \mathrm{m}$ cellulose acetate filters (Sigma, USA) prior to 
cytokine/chemokine measurements, to exclude debris. All values below the detection limit were recorded as half of the lowest measured concentration for each cytokine. In addition, HeLa cell total RNA was extracted using TRIzol ${ }^{\circledR}$ reagent (Invitrogen, US) and complementary DNA (cDNA) was synthesized from 200 ng/ $\mu$ l RNA using MultiScribe ${ }^{\mathrm{TM}}$ Reverse Transcriptase (Applied Biosystems, US), following the manufacturer's protocol. Primer sets for target genes, including IL-1 $\beta$, IL-6, IL-8, GM-CSF, MIP$3 \alpha$, VEGF, and human cyclophilin A (included as a house keeping gene) were designed (Supplementary Table 1) and PCR reaction conditions optimized for each primer pair. Quantitative real time qPCR was performed in duplicates by using SensiMix SYBR ${ }^{\circledR}$ No-ROX on Eco ${ }^{\mathrm{TM}}$ Real time PCR system (Illumina ${ }^{\mathrm{TM}}$, US). Expression of mRNA for each of the target genes was normalized to the house-keeping gene human cyclophilin A and reported as relative expression.

\section{Statistical Analyses}

Descriptive statistics were used to describe demographic characteristics. Fisher's exact test and Wilcoxon rank sums tests were used to compare categorical variables and continuous data between groups, respectively. To compare between control and experimental qPCR data at each time point, a Wilcoxon matched pairs (non-parametric) or a standard matched pairs $t$-tests (parametric) were performed to determine if there was a significant difference in inflammatory cytokine mRNA expression in control and seminal plasma-treated cells. A confidence interval of $95 \%(p<0.05)$ was selected as a cutoff point. To assess the effect of seminal plasma on cytokine concentrations, a linear regression model was fitted to logtransformed cytokine concentrations. Pearsons' correlation was used to evaluate the relationship between cytokine mRNA induction and protein concentrations. Adjustment for multiple comparisons was conducted using the false discovery rate to reduce false positive results. Statistical analyses were performed using SAS version 9.3 (SAS Institute Inc., Cary) and Graphpad Prism version 5 (GraphPad Software Inc., US).

\section{RESULTS}

\section{Characteristics of the Cohort}

Semen collected from $28 \mathrm{HIV}$-negative and $38 \mathrm{HIV}$-positive heterosexual South African men were used for this study (Table 1) (3). The male donors median age was 42 years (range 23-58), which did not differ significantly by HIV status, and the majority (93\%) were circumcised. Of the $38 \mathrm{HIV}$-positive men, $12 / 38(31.6 \%)$ were on HAART (HAART + ). The median plasma viral load in HIV-positive, HAART negative men was 10200 RNA copies/ml (IQR 2250-40000 RNA copies/ml), significantly higher than the matching median seminal viral load of HIV-positive men on HAART (1389 RNA copies/ml; IQR undetectable-20060 RNA copies/ml). The majority of HIV positive HAART negative men were shedding HIV in semen $(73.1 \%, 19 / 26)$ and the viral shedding into the semen was correlated with HIV concentration in blood $(p=0.04$, Rho $=0.4)$. In addition, 4/28 (14.3\%) HIV-negative and 9/38 (23.7\%) HIV-positive men tested positive for STIs (N. Gonorrhea, C. trichomatis, T. vaginalis, and $M$. genitalium), which did not differ significantly by HIV status ( $p$ $=0.51$ Fishers' exact test).

\section{Seminal Plasma Cytokine Profiles}

We previously reported that inflammatory, adaptive and regulatory cytokines were present in higher concentrations in semen than in matching blood samples with MCP-1, IL-8, Fractalkine, GM-CSF, MIP-1 $\beta$, IL-7, IL-15, and IL-10 being detected at significantly higher concentrations in seminal plasma than in blood (3). Cytokines present at the highest concentrations in seminal plasma were MCP-1 (medians ranging from 829 to $13,064 \mathrm{pg} / \mathrm{ml}$ ), MIG (12,221 to $15,003 \mathrm{pg} / \mathrm{ml}$ ), RANTES (67 to $2,448 \mathrm{pg} / \mathrm{ml}$ ), and IL-8 (220 to $3,183 \mathrm{pg} / \mathrm{ml}$ ) (data not shown). Compared to MIG and MCP-1, TGF- $\beta$ was detected at 15- to 150 -fold lower concentrations, with TGF- $\beta 3$ being present at the highest concentrations and TGF- $\beta 2$ at the lowest. As we have previously reported, seminal plasma cytokines were present in similar concentrations in HIV-infected and uninfected men (3).

\section{Selection of Seminal Plasma With High or Low Relative Cytokine Profiles}

From the 28 semen samples from HIV-negative men, five samples with the highest cumulative levels of inflammation (high inflammation) and five with the lowest cumulative levels of inflammation (low inflammation) were pooled for further analysis of the effects of semen and respective cytokine profiles on inflammatory responses by cervical Hela cells. Similarly, from the 35 semen samples from HIV-positive men, five samples with high relative cytokine concentrations and five with relatively low cytokine concentrations were pooled. To confirm that pooled seminal plasma were representative of high vs. low inflammation cytokine profiles, we performed an unsupervised hierarchical cluster analysis (Figure 1). Seminal plasma pools representing the highest relative cytokine concentrations and

TABLE 1 | Clinical characteristics of men included in this study.

\begin{tabular}{|c|c|c|}
\hline Characteristic & HIV-infected & HIV-uninfected \\
\hline Number & 38 & 28 \\
\hline Age [years; median (IQR)] & $39(34-44)$ & $44(37-51)$ \\
\hline $\begin{array}{l}\text { CD4 count [cell/ } / \mathrm{mm}^{3} ; \\
\text { median (IQR)] }\end{array}$ & $391(278-507)$ & - \\
\hline Number of men on HAART & 12/38 (31.6\%) & \\
\hline $\begin{array}{l}\text { Plasma viral load [RNA } \\
\text { copies/ml; median (IQR)] }]^{1}\end{array}$ & 10200 (2250-40000) & - \\
\hline $\begin{array}{l}\text { Genital tract viral load [RNA } \\
\text { copies/ml; median (IQR)] }{ }^{1}\end{array}$ & $1389\left(\mathrm{LDL}^{2}-20060\right)$ & - \\
\hline $\begin{array}{l}\text { Number of men with } \\
\text { detectable HIV RNA in } \\
\text { semen [N/Total (\%)] }\end{array}$ & 21/38 (55.3\%) & - \\
\hline Presence of STIs $(\%)^{3}$ & $9 / 38$ (23.7\%) & $4 / 28(14.3 \%)$ \\
\hline
\end{tabular}

${ }^{1}$ Including only the 26/38 HIV+ men not taking HAART.

${ }^{2} L D L$, less than detectable limit (70 HIV-1 RNA copies $/ \mathrm{ml}$ ).

${ }^{3}$ STIs included Neisseria Gonorrhea, Chlamydia trichomatis, Trichomonas vaginalis, and Mycoplasma genitalium. 

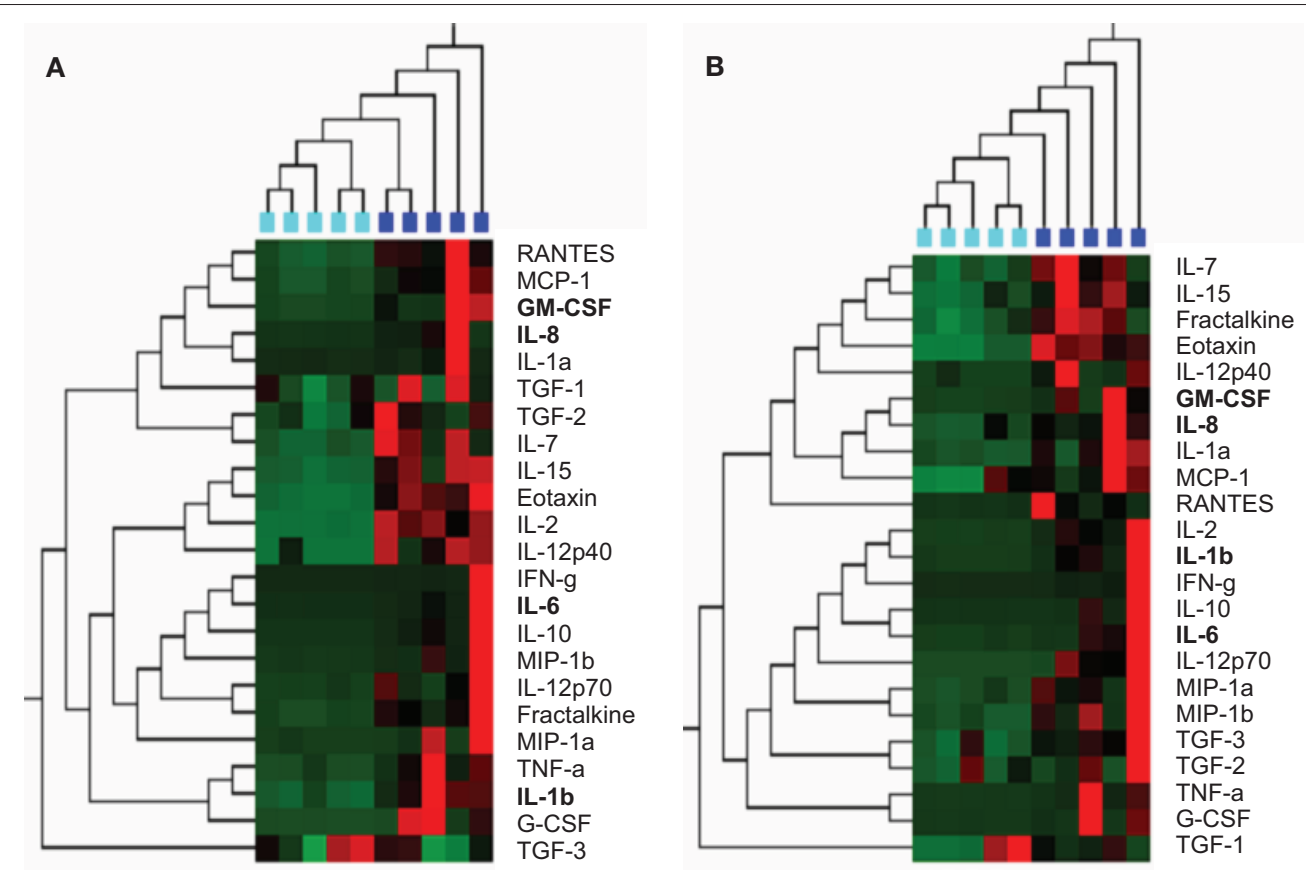

FIGURE 1 | Unsupervised hierarchical clustering confirmed selection of semen from the HIV-negative (A) and HIV-positive (B) men by cytokine concentration; and to cluster men according to the similarities of their semen cytokine expression profiles (using Qlucore Omics Explorer). (A) HIV-negative men with the lowest concentrations of 23 cyokines ( $n=5$; turquoise blocks) clustered separately from HIV-negative men with the highest concentrations of these cytokines $(n=5$; blue blocks). (B) HIV-positive men with the lowest concentrations of 23 cyokines ( $n=5$; turquoise blocks) clustered separately from HIV-positive men with the highest concentrations of these cytokines $(n=5$; blue blocks). Cytokine concentrations are indicated using a color scale, ranging from green (low) to red (high). The dendrogram above the heat map illustrates degrees of relatedness between cytokine profiles evident within semen from the various men. In this tree, shorter and longer horizontal branch path lengths between pairs of cytokines, respectively reflect greater and lower degrees of similarity between the expression profiles of the assessed cytokines. Cytokines shown in bold indicate those that were measured in the in vitro experiments in this study.

the lowest cytokine concentrations from HIV-negative and HIVpositive men clustered separately using unsupervised hierarchical clustering of relative cytokine levels. In contrast, seminal plasma pools representing the highest relative cytokine concentrations from HIV-negative and HIV-positive men clustered together and the same was observed for seminal plasma pools representing the lowest cytokine concentrations from HIV-negative and HIVpositive men. Table 2 provides a detailed summary of the panel of cytokines that were measured in the semen samples selected for each of these pools, similarly reflecting the fact that the low and high semen inflammation pools were significantly different for 18/26 cytokines measured for HIV \pm men and 19/26 cytokines measured for HIV- men. In semen, irrespective of HIV status, MIG and MCP-1 was detected at the highest concentrations while IL-12p70 were detected at the lowest concentrations.

\section{Seminal Plasma Increased Cytokine Expression by Cervical Cells}

We compared cytokine mRNA expression after exposing HeLa cervical cells for 8 and $24 \mathrm{~h}$ with pooled seminal plasma from men with either low or high levels of inflammatory mediators (Figure 2). IL-8 mRNA expression was 5- to 10-fold increased following $8 \mathrm{~h}$ of exposure to semen with low- or high levels of inflammatory phenotype compared to mock exposed HeLa cells $(p<0.05$ for HIV- high inflammation semen, and for both high- and low inflammation semen from $\mathrm{HIV} \pm$ semen), and occurred irrespective of HIV status of the semen donors (Figure 2B). IL-8 mRNA expression remained elevated at $24 \mathrm{~h}$ (significantly so for HIV+ high inflammation semen), although fold expression had decreased compared to the $8 \mathrm{~h}$ time point. IL$1 \beta$ mRNA expression was elevated at $8 \mathrm{~h}$ in cervical cells exposed to seminal plasma with high ( $p<0.05$ for both HIV + and HIVsemen) but not low levels of inflammatory molecules, which was similar in HIV positive and HIV negative seminal plasma pools (Figure 2C). IL-1 $\beta$ was further increased by $24 \mathrm{~h}$, with mRNA being elevated in the presence of seminal plasma, regardless of the level of seminal plasma inflammation or HIV status. At the earlier time point, IL-6, MIP-3 $\alpha$, GM-CSF, and VEGF mRNA expression was not elevated compared to the control (Figures 2A,D-F). By 24 h, IL-6 mRNA expression was elevated in cells exposed to seminal plasma (Figure 2A), although this elevation was only significant for semen from HIV+ men with high levels of cytokines. GM-CSF (Figure 2E) expression was also only notably elevated at $24 \mathrm{~h}$ and not $8 \mathrm{~h}$ of exposure. While, VEGF and MIP-3a mRNA did not appear to be significantly elevated at either the earlier or later time point (Figures 2D,F).

Next, we determined cytokine production following exposure of HeLa cervical cells for 8 and $24 \mathrm{~h}$ with pooled seminal plasma (Figure 3). Protein concentrations were measured for four of the six cytokines for which mRNA (IL-6, IL-8, GM-CSF, and VEGF), 
TABLE 2 | Cytokine concentrations in semen from HIV-infected and uninfected men with either high or low inflammation.

\begin{tabular}{|c|c|c|c|c|c|c|}
\hline \multirow[t]{2}{*}{ Cytokine } & \multicolumn{2}{|c|}{ HIV-infected [median pg/ml (IQR)] } & \multirow[t]{2}{*}{$P$-value } & \multicolumn{2}{|c|}{ HIV uninfected [median pg/mI (IQR)] } & \multirow[t]{2}{*}{$P$-value } \\
\hline & High inflammation & Low inflammation & & High inflammation & Low inflammation & \\
\hline $\mathrm{IL}-1 \alpha$ & $147.2(61.5-616.7)$ & $6.4(4.9-11.0)$ & $<0.05$ & $12.5(6.6-793.0)$ & $15.0(1.7-39.3)$ & $\mathrm{ns}$ \\
\hline $\mathrm{IL}-1 \beta$ & $9.1(2.4-199.9)$ & $0.02(0.01-0.1)$ & $<0.05$ & $1.0(0.1-3.0)$ & $0.3(0.04-51.9)$ & $<0.01$ \\
\hline IL-6 & $372.8(0.7-1116.2)$ & $7.9(0.4-20.5)$ & $<0.01$ & $92.7(3.0-2635.2)$ & $5.6(1.3-164.2)$ & $<0.01$ \\
\hline IL-8 & $3183.3(119.2-9434.6)$ & $270.1(51.5-1771.8)$ & $<0.05$ & $808.1(161.4-18277.2)$ & $220.4(51.4-1841.4)$ & ns \\
\hline MCP-1 & $13064.2(2.3-28069.5)$ & $829.0(133.3-15539.6)$ & ns & $14293.3(2580.1-67443.7)$ & $4077.0(129.2-22424.9)$ & $<0.01$ \\
\hline MIG & 15003.5 (9598.9-34675.5) & $12221.6(3528.8-12221.6)$ & ns & 13790.8 (9533.4-48812.6) & 12637.3 (399-16802.6) & $<0.05$ \\
\hline $\mathrm{MIP}-1 \alpha$ & 249.5 (113.5-8658.7) & $8.1(1.3-19.1)$ & $<0.05$ & $4.9(1.3-508.5)$ & $6.9(1.3-25.0)$ & $<0.05$ \\
\hline MIP-1 $\beta$ & $262.3(37.4-691.3)$ & $21.1(10.8-48.2)$ & $<0.01$ & 97.5 (23.9-1899.7) & $33.3(15.6-196.3)$ & $<0.05$ \\
\hline $\mathrm{MIP}-3 \alpha$ & $6.2(2.9-70.9)$ & $0.4(0.2-0.5)$ & ns & $70.6(7.1-630.1)$ & $27.1(2.0-161.8)$ & $<0.01$ \\
\hline TNF- $\alpha$ & 109.3 (64.9-1082.7) & 18.8 (2.3-99.9) & $<0.01$ & $6.6(0.3-50.0)$ & $2.1(0.2-16.5)$ & $<0.05$ \\
\hline RANTES & 2448.0 (764.7-3502.8) & $67.2(40.6-117.2)$ & $<0.01$ & $468.9(72.5-1227.7)$ & 114.1 (36.4-613.4) & $<0.01$ \\
\hline IL-2 & $5.7(2.7-23.8)$ & $0.2(0.02-0.3)$ & $<0.01$ & $4.7(0.02-8.3)$ & $0.1(0.02-7.3)$ & $<0.05$ \\
\hline IL-7 & 2407.8 (1015.6-3216.0) & 374.1 (145.6-575.2) & $<0.05$ & $677.1(134.1-3803.6)$ & $258.4(0.9-2667.4)$ & $<0.01$ \\
\hline IL-10 & 53.9 (7.9-1066.3) & $4.1(0.7-4.9)$ & ns & 166.6 (2.7-2959.9) & 3.5 (1.6-294.2) & $<0.01$ \\
\hline IL-12p40 & $25.7(5.0-31.8)$ & $1.3(1.3-2.4)$ & $<0.05$ & $2.6(1.3-4.9)$ & $1.9(1.3-4.5)$ & ns \\
\hline IL-12p70 & $2.0(0.9-7.1)$ & $0.02(0.02-0.02)$ & $<0.05$ & $0.02(0.5-11.6)$ & $0.2(0.02-2.7)$ & $<0.05$ \\
\hline IL-15 & $62.8(34.7-1161.8)$ & $8.1(3.7-24.1)$ & $<0.01$ & $30.9(6.6-87.6)$ & $7.6(3.9-69.0)$ & $<0.01$ \\
\hline IFN- $\gamma$ & $35.7(17.2-552.1)$ & $2.0(0.9-2.3)$ & $<0.05$ & $24.3(0.3-1520.5)$ & $1.5(0.03-35)$ & $<0.05$ \\
\hline G-CSF & 59.9 (20.6-1700.3) & $7.8(1.7-11.2)$ & $<0.01$ & 57.2 (7.9-1482.3) & 15.8 (5.3-631.3) & $<0.01$ \\
\hline GM-CSF & $20.6(3.7-73.5)$ & $1.6(0.4-1.9)$ & $<0.05$ & $3.2(0.5-48.9)$ & $0.7(0.03-9.2)$ & $<0.01$ \\
\hline Eotaxin & $38.1(29.3-48.2)$ & $2.4(2.1-7.8)$ & $<0.05$ & $44.1(3.7-83.1)$ & $5.2(2.1-55.8)$ & $<0.05$ \\
\hline Fractalkin & $1085.1(23.2-1567.0)$ & $160.1(63.0-351.1)$ & $<0.05$ & $215.2(152.1-5957.2)$ & 234.8 (1.9-2068.6) & $<0.05$ \\
\hline ITAC & 1812.7 (833.1-1912.3) & 414.6 (9.0-460.9) & ns & $666.2(269.7-1402.7)$ & 689.5 (1.9-937.7) & ns \\
\hline
\end{tabular}

in addition to TNF- $\alpha$ and MCP-1. Similar to the difference between seminal plasma with low vs. high inflammatory markers in IL-8 mRNA expression by HeLa cells, IL-8 protein concentrations were higher following stimulation with seminal plasma having higher concentrations of inflammatory cytokines in comparison to seminal plasma with lower concentrations of cytokines, irrespective of HIV status (Figure 3A). The seminal plasma with lower concentrations of inflammatory cytokines yielded significantly elevated IL- 8 expression by $24 \mathrm{~h}$ (but not $8 \mathrm{~h}$ ). While IL-6 mRNA expression was only evident at $24 \mathrm{~h}$ and was most evident when the cells were exposed to seminal plasma with high inflammation profile, IL-6 protein expression was significantly elevated at 8 and $24 \mathrm{~h}$ of exposure (Figure 3B). Seminal plasma with high inflammation profiles tended to induce more IL-6 protein expression than seminal plasma with low inflammation profiles, at both 8 and $24 \mathrm{~h}$. GMCSF and VEGF, both important growth factors that stimulate proliferation and maturation of lymphocytes and the formation of blood vessels, respectively, showed a similar profile of no to modest induction of mRNA (Figures 2E,F) associated with more clearly detectable induction of protein expression (Figures 3E,F). Protein expression of both of these growth factors appeared to peak early $(8 \mathrm{~h})$. While GM-CSF concentrations were higher after exposure to the high inflammation seminal plasma compared to the low inflammation seminal plasma, inflammatory status of seminal plasma did not appear to influence the induction of VEGF by HeLa cells. Comparing protein concentrations with mRNA induction for the four cytokines for which both measurements were performed, a moderate significant positive correlation was observed at $8 \mathrm{~h}$ (Pearson $R^{2}=0.2617 ; p=0.04$ ) but not at $24 \mathrm{~h}$ (Pearson $R^{2}=-0.0961 ; p=0.2$ ).

TNF- $\alpha$ and MCP-1 concentrations tended to be induced early (Figures 3C,D), with TNF- $\alpha$ levels dropping to baseline by $24 \mathrm{~h}$. The HIV status of semen donors did not appear to play a major role in induction of TNF- $\alpha$, although MCP-1 concentrations appeared to be higher in the presence of seminal plasma from HIV-negative men with high levels of inflammation.

\section{DISCUSSION}

In addition to semen being a vehicle for spermatozoa delivery, it contains various immunological factors, including cytokines and chemokines that may influence the microenvironment within the female genital tract (2-4). This study focused on the effects of semen on inflammatory responses (mRNA and protein) in vitro by cervical epithelial cells. We found that semen resulted in significantly elevated secretion of IL-6, IL-8, TNF- $\alpha$, MCP-1, GM-CSF, and VEGF within $8 \mathrm{~h}$ of stimulation, which declined by $24 \mathrm{~h}$ for the majority of cytokines. Irrespective of male HIV status or semen inflammatory profile, cervical cells responded to seminal plasma with increases in IL- 8 and IL- $1 \beta$ mRNA expression of 10 -fold after $8 \mathrm{hr}$ exposure. 


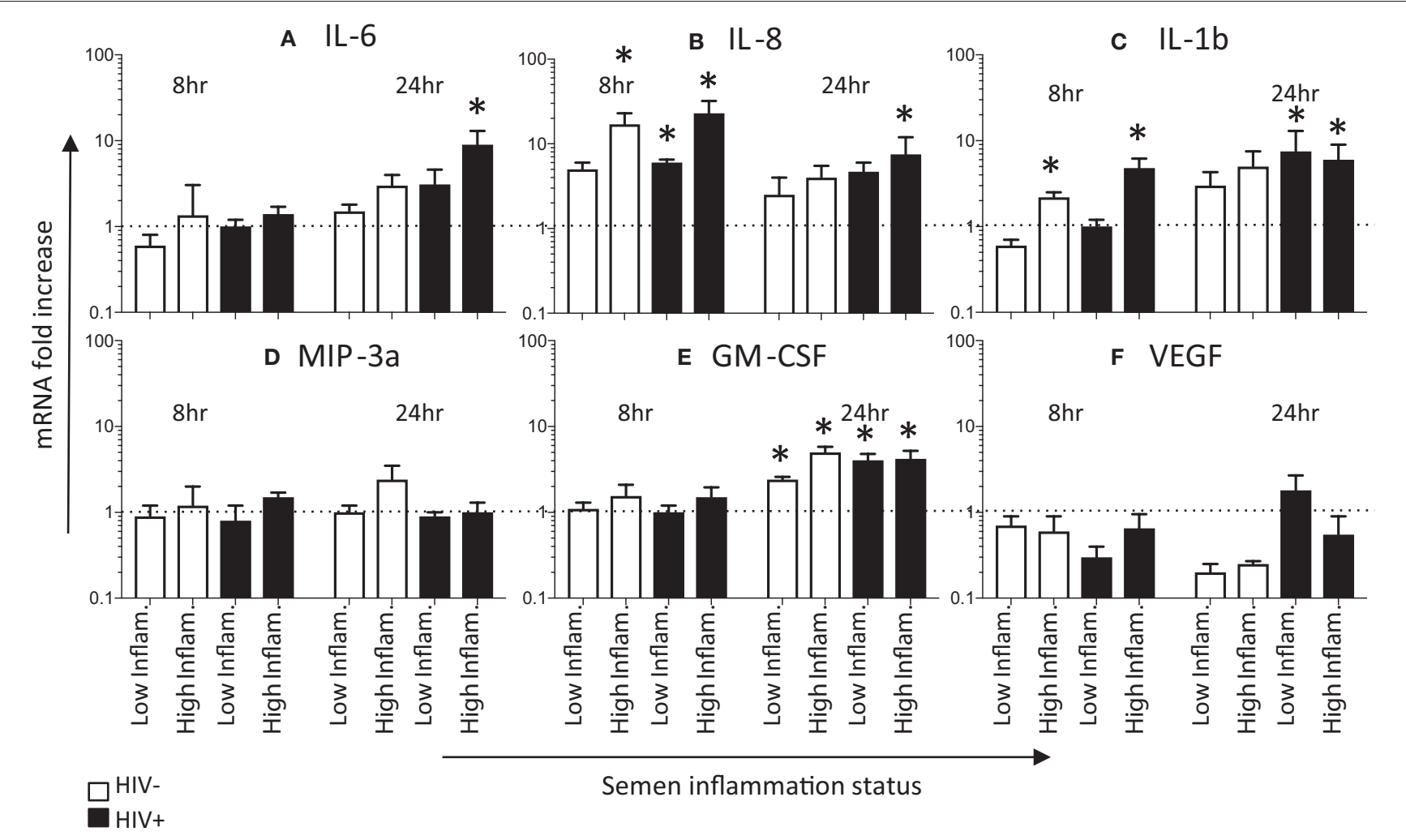

FIGURE 2 | Effects of seminal plasma on cytokine mRNA expression by HeLa cells. Quantitative real-time PCR was used to determine the mRNA expression of (C) IL-6, (A) IL-8, (B) IL-1 $\beta$, (E) GM-CSF, (D) MIP3 $\alpha$, and (F) VEGF by HeLa cells treated with 1:50 dilution of seminal plasma from HIV-negative (white bars) or HIV-positive individuals (black bars) for $8 \mathrm{~h}(n=4)$ and $24 \mathrm{~h}(n=3)$. The mRNA levels were normalized by housekeeping gene Human cyclophilin A. Data are represented as the mean \pm SEM of duplicate wells in each experiment. Wilcoxon matched pairs (non-parametric) and standard matched pairs $t$-tests (parametric) were used to compare the control and treatment groups. ${ }^{*} p<0.05$.

Semen selected for this study was collected from HIVnegative and HIV-positive men with either low or high relative concentrations of 23 cytokines. As we have previously reported, MCP-1, MIG, RANTES, and IL-8 were all detected at high concentrations in semen, irrespective of HIV status (3). MCP-1 is a chemoattractant for monocytes, dendritic cells, and T cells $(14,15)$, MIG and RANTES are chemoattractants for T cells (16) while IL- 8 is a potent chemokine that is involved in neutrophil chemotaxis (17). TGF- $\beta$, previously reported to be present in high concentrations in semen $(10,18-20)$, exists in different isoforms (TGF- $\beta 1, \beta 2, \beta 3$, and $\beta 4$ ) with close genetic relatedness, which plays an important role in normal growth and development (18-20), but is also central to many inflammatory processes at mucosal surfaces (10).

Both in vitro and in vivo studies have shown that female genital tract cervicovaginal cells exposed to seminal plasma have increased expression of GM-CSF, IL- 6 , IL-8, MCP-1, MIP-3 $\alpha$, IL- $1 \alpha$, and IL- $1 \beta(4,6,10,21)$. This study was consistent with these previous findings, confirming the hypothesis that semen up-regulates pro-inflammatory gene expression in cells of the female genital tract. IL-8 in particular has been shown to promote HIV-1 infection (22) and the increase in IL- 8 mRNA and protein expression following exposure to seminal plasma was found to be the greatest of all the cytokines evaluated in this study. IL$1 \beta$ (together with TNF- $\alpha$ ) has also been regarded as one of the main triggers of expression of pro-inflammatory cytokines and IL-1 $\beta$ mRNA was also one of the cytokine with the highest foldinduction in cervical cells following exposure to seminal plasma (23). This suggests that there is an inflammatory reaction that may be induced post-coitus during unprotected heterosexual intercourse, as shown in vivo (6).

To assess the biological significance of mRNA induction by HeLa cells following stimulation via seminal plasma, protein levels of IL-8, IL-6, GM-CSF, VEGF, TNF- $\alpha$, and MCP-1 were measured. As with mRNA expression, cytokine concentrations (IL-6, IL-8, GM-CSF, VEGF, TNF- $\alpha$, and MCP-1) were significantly increased in $8 \mathrm{~h}$ treated HeLa cell supernatants while only concentrations of IL-6, IL-8, GM-CSF, and VEGF remained significantly high after $24 \mathrm{~h}$ stimulation, irrespective of HIV and inflammatory status. Our findings confirm the hypothesis that seminal plasma up-regulates pro-inflammatory gene expression at both the mRNA and the protein levels. However, the cytokine mRNA induction correlated significantly with their protein levels only at $8 \mathrm{~h}$ but not at $24 \mathrm{~h}$. This suggests that cytokine mRNA transcript abundances predicted cytokine protein concentrations only at the earlier time point. 


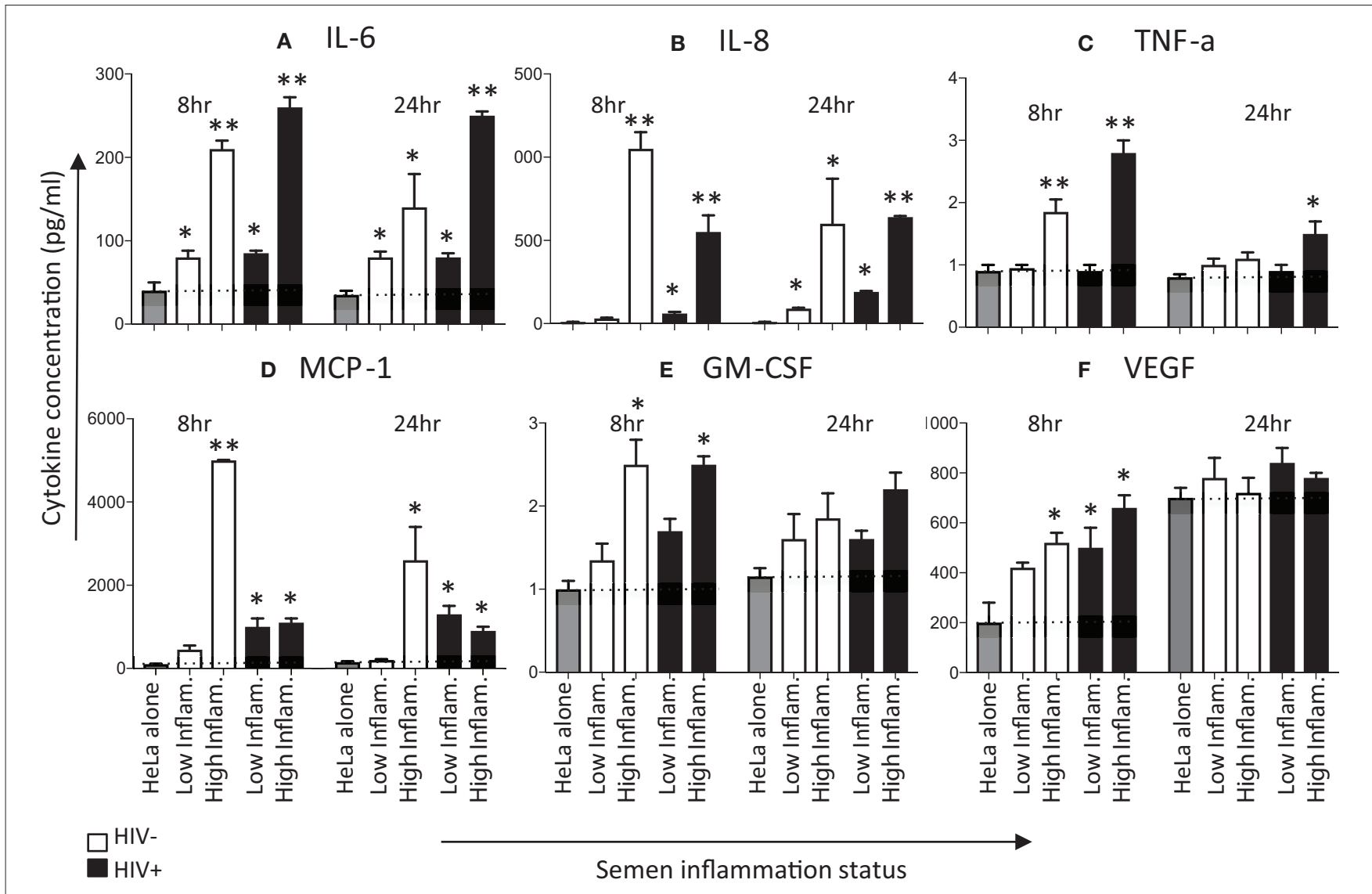

FIGURE 3 | Effects of seminal plasma on cytokine secretion by HeLa cells. Hela cells were exposed to seminal plasma from HIV-negative (white bars) or HIV-infected individuals (black bars). A 1:50 dilution of seminal plasma from men with extreme inflammatory profiles (highest vs. lowest percentile) were used to stimulated HeLa cells for 8 and $24 \mathrm{~h}$. Cytokine levels was measured in the 8 and $24 \mathrm{~h}$ post-stimulation in Hela cells supernatants by Luminex. Seminal plasma (1:50) in serum free culture media was used, while control was serum free culture media. Data are represented as the mean \pm SEM of duplicate wells in each experiment. Wilcoxon matched pairs (non-parametric) and a standard matched pairs $t$-tests (parametric) were used to compare the control and treatment groups. ${ }^{*} p<0.05$; ${ }^{* *} p<0.01$. (A) IL-6, (B) IL-8, (C) TNF- $\alpha$, (D) MCP-1, (E) GM-CSF, and (F) VEGF.

It was not clear why mRNA and protein levels correlated better at the earlier than later time point but this may be due to kinetic differences in mRNA expression and protein translation.

Although the effect of seminal plasma on the female genital epithelial tract has been measured in vitro (4), previous studies considered semen to be quite homogenous and have not considered the influential role of pro- and anti-inflammatory mediators present within seminal plasma on local female genital tract immune responses. The results from this study suggest that there is a relationship between the inflammatory cytokine content of seminal plasma and the extent of inflammatory cytokine mRNA expression they induce in Hela cells. This implies that men with higher cytokine levels in their seminal plasma may enhance inflammatory response in their female partners. Since this inflammatory response is characterized by cytokines that increase risk of HIV infection, this finding may suggest that males with high inflammatory profiles in their seminal plasma may put their female sexual partners at a higher risk for HIV infection.
From a survey performed on $>1,000$ men undergoing fertility testing, the mean volume of ejaculate produced was $3.8 \mathrm{ml}$ (range 0.1-11.3) (24), which is a considerably higher concentration that the 1:50 dilution of seminal plasma we used in this and previous studies from our and other groups (25-27). Seminal fluid exerts no effect on HeLa cell viability at concentrations $\leq 1: 50$ (27). Since the aim of this study was to compare semen with high vs. low levels of inflammatory mediators on cervical cells, maintenance of HeLa cell viability was obviously a major consideration in selecting the concentration of seminal plasma to use. It is well-appreciated that this intrinsic toxicity of semen is related to the fact that post-ejaculation spermatozoon rapidly undergo apoptosis, via Fas-FasL interactions, apart from the few spermatozoa that successfully fertilize oocytes (28). Although we processed whole ejaculates from men within $4 \mathrm{~h}$. of collection, it is possible that apoptosis of spermatozoa in the whole sample would have contributed to the toxicity potential of seminal plasma $(27,28)$, that would be independent of the inflammatory signals that semen plasma exert in the female reproductive tract which we were seeking to evaluate. 
One of the limitations for using HeLa cells as a model for female genital cervicovaginal epithelial cell cytokine production is that these cells exhibit significantly different gene expression patterns from those in normal human tissues (29). While this means that extrapolation from the findings in this study to primary genital tract epithelial cells are not universal, the fact that this cell line is so well-characterized and homogenous in responses makes it a useful starting point for this type of study. Using three-dimensional genital cell cultures, like biopsy explant tissues (30), or organ-on-a-chip technology (31) could be considered in future studies. Another limitation of our study was that we did not measure sperm counts in the ejaculates, which may have influence their immunemodulatory potential. Von Wolff et al. (32) found that the immune-modulatory effect of seminal plasma was not associated with sperm counts. Furthermore, whole ejaculate samples were centrifuged immediately prior to semen supernatant removal, suggesting that the sperm component of the ejaculate was no longer present at the time the semen plasma was applied to the cervical cell line. We also did not exclude men with other STIs as these are major drivers of genital inflammation in men, and we considered it relevant to include infectious, as well as, noninfectious causes of inflammation in the semen donors that we selected.

In conclusion, we found that male seminal plasma up-regulates pro-inflammatory cytokine expression by cervical epithelial cells, and that the pattern of the cytokine concentrations in seminal plasma influences the extent to which this up-regulation occurs in $\mathrm{HeLa}$ cells. Furthermore, these findings suggest that the impact of semen on local female genital cytokines peaks relatively early following exposure and that changes may not be sustained long-term. This increased, albeit transient inflammatory response may elevate the risk of HIV acquisition in women during unprotected sex.

\section{REFERENCES}

1. Doncel GF, Anderson S, Zalenskaya I. Role of semen in modulating the female genital tract microenvironment-implications for HIV transmission. Am J Reprod Immunol. (2014) 71:564-74. doi: 10.1111/aji.12231

2. Denison FC, Grant VE, Calder AA, Kelly RW. Seminal plasma components stimulate interleukin-8 and interleukin-10 release. Mol Hum Reprod. (1999) 5:220-6. doi: 10.1093/molehr/5.3.220

3. Olivier AJ, Masson L, Ronacher K, Walzl G, Coetzee D, Lewis DA, et al. Distinct cytokine patterns in semen influence local HIV shedding and HIV target cell activation. J Infect Dis. (2014) 209:1174-84. doi: 10.1093/infdis/jit649

4. Sharkey DJ, Macpherson AM, Tremellen KP, Robertson SA. Seminal plasma differentially regulates inflammatory cytokine gene expression in human cervical and vaginal epithelial cells. Mol Hum Reprod. (2007) 13:491-501. doi: 10.1093/molehr/gam028

5. Gutsche S, von Wolff M, Strowitzki T, Thaler CJ. Seminal plasma induces mRNA expression of IL-1beta, IL-6 and LIF in endometrial epithelial cells in vitro. Mol Hum Reprod. (2003) 9:785-91. doi: 10.1093/molehr/gag095

6. Sharkey DJ, Tremellen KP, Jasper MJ, Gemzell-Danielsson K, Robertson SA. Seminal fluid induces leukocyte recruitment and cytokine and chemokine mRNA expression in the human cervix after coitus. J Immunol. (2012) 188:2445-54. doi: 10.4049/jimmunol.1102736

7. Kachkache M, Acker GM, Chaouat G, Noun A, Garabedian M. Hormonal and local factors control the immunohistochemical distribution of immunocytes

\section{AUTHOR CONTRIBUTIONS}

CR performed all the laboratory work, analyzed the data, and prepared the manuscript. J-AP conceptualized the study, supervised $\mathrm{CR}$, analyzed the data, and co-wrote the manuscript. AO conceptualized the study, supervised CR, and helped prepare the manuscript. AA and AK supervised CR, assisted with some of the laboratory work, and contributed to the writing of the manuscript. WB conceptualized the male semen study and contributed to the writing of the manuscript. DL performed STI testing of male donors from which semen was derived, advised on data interpretation, and helped prepare the manuscript. LC analyzed the data and helped prepare the manuscript. ALW provided funding and oversight for the parent study from which the male semen donors were derived, advised on data interpretation, and helped write the manuscript. HG supervised $\mathrm{CR}$ and helped prepare the manuscript.

\section{FUNDING}

Funding for this study was provided by South African MRC SHARP (South African HIV AIDS Research Platform; PI: J-AP).

\section{ACKNOWLEDGMENTS}

We thank the men who participated in the study and kindly provided semen. We thank Dr. Lindi Masson for her help with generating Figure 1 and guidance in the luminex assays.

\section{SUPPLEMENTARY MATERIAL}

The Supplementary Material for this article can be found online at: https://www.frontiersin.org/articles/10.3389/fimmu. 2018.02721/full\#supplementary-material

in the rat uterus before conceptus implantation: effects of ovariectomy, fallopian tube section, and injection. Biol Reprod. (1991) 45:860-8. doi: 10.1095/biolreprod45.6.860

8. McMaster MT, Newton RC, Dey SK, Andrews GK. Activation and distribution of inflammatory cells in the mouse uterus during the preimplantation period. J Immunol. (1992) 148:1699-705.

9. Prakash M, Patterson S, Gotch F, Kapembwa MS. Recruitment of CD4 T lymphocytes and macrophages into the cervical epithelium of women after coitus. Am J Obstet Gynecol. (2003) 188:376-81. doi: 10.1067/mob.2003.16

10. Sharkey DJ, Macpherson AM, Tremellen KP, Mottershead DG, Gilchrist RB, Robertson SA. TGF-beta mediates proinflammatory seminal fluid signaling in human cervical epithelial cells. J Immunol. (2012) 189:1024-35. doi: 10.4049/jimmunol.1200005

11. Walsh TL, Frezieres RG, Peacock K, Nelson AL, Clark VA, Bernstein L, et al. Use of prostate-specific antigen (PSA) to measure semen exposure resulting from male condom failures: implications for contraceptive efficacy and the prevention of sexually transmitted disease. Contraception (2003) 67:139-50. doi: 10.1016/S0010-7824(02)00478-X

12. Lewis DA, Muller E, Steele L, Sternberg M, Radebe F, Lyall M, et al. Prevalence and associations of genital ulcer and urethral pathogens in men presenting with genital ulcer syndrome to primary health care clinics in South Africa. Sex Transm Dis. (2012) 39:880-5. doi: 10.1097/OLQ.0b013e318269cf90

13. Jeremias JC, Bongiovanni AM, Witkin SS. Induction of heat shock protein expression in cervical epithelial cells by human semen. Infect Dis Obstet Gynecol. (1999) 7:17-22. doi: 10.1155/S1064744999000046 
14. Carr MW, Roth SJ, Luther E, Rose SS, Springer TA. Monocyte chemoattractant protein 1 acts as a T-lymphocyte chemoattractant. Proc Natl Acad Sci USA. (1994) 91:3652-6. doi: 10.1073/pnas.91.9.3652

15. Deshmane SL, Kremlev S, Amini S, Sawaya BE. Monocyte chemoattractant protein-1 (MCP-1): an overview. J Interferon Cytokine Res. (2009) 29:313-26. doi: 10.1089/jir.2008.0027

16. Lane TE, Liu MT, Chen BP, Asensio VC, Samawi RM, Paoletti AD, et al. A central role for CD4(+) T cells and RANTES in virus-induced central nervous system inflammation and demyelination. J Virol. (2000) 74:1415-24. doi: 10.1128/JVI.74.3.1415-1424.2000

17. Gessler P, Pretre R, Hohl V, Rousson V, Fischer J, Dahinden C. CXC-chemokine stimulation of neutrophils correlates with plasma levels of myeloperoxidase and lactoferrin and contributes to clinical outcome after pediatric cardiac surgery. Shock (2004) 22:513-20. doi: 10.1097/01.shk.0000145939.54838.51

18. Nocera M, Chu TM. Characterization of latent transforming growth factorbeta from human seminal plasma. Am J Reprod Immunol. (1995) 33:282-91. doi: 10.1111/j.1600-0897.1995.tb00897.x

19. Robertson SA, Seamark RF, Guilbert LJ, Wegmann TG. The role of cytokines in gestation. Crit Rev Immunol. (1994) 14:239-92. doi: 10.1615/CritRevImmunol.v14.i3-4.30

20. Sharkey AM, Dellow K, Blayney M, Macnamee M, Charnock-Jones S, Smith SK. Stage-specific expression of cytokine and receptor messenger ribonucleic acids in human preimplantation embryos. Biol Reprod. (1995) 53:974-81. doi: 10.1095/biolreprod53.4.974

21. Khan KN, Kitajima M, Hiraki K, Fujishita A, Sekine I, Ishimaru T, et al. Effect of human seminal fluid on the growth of endometrial cells of women with endometriosis. Eur J Obstet Gynecol Reprod Biol. (2010) 149:204-9. doi: 10.1016/j.ejogrb.2009.12.022

22. Olsson J, Poles M, Spetz AL, Elliott J, Hultin L, Giorgi J, et al. Human immunodeficiency virus type 1 infection is associated with significant mucosal inflammation characterized by increased expression of CCR5, CXCR4, and beta-chemokines. J Infect Dis. (2000) 182:1625-35. doi: 10.1086/ 317625

23. Sturm-Ramirez K, Gaye-Diallo A, Eisen G, Mboup S, Kanki PJ. High levels of tumor necrosis factor-alpha and interleukin-1beta in bacterial vaginosis may increase susceptibility to human immunodeficiency virus. J Infect Dis. (2000) 182:467-73. doi: 10.1086/315713

24. Cooper TG, Brazil C, Swan SH, Overstreet JW. Ejaculate volume is seriously underestimated when semen is pipetted or decanted into cylinders from the collection vessel. J Androl. (2007) 28:1-4. doi: 10.2164/jandrol.106.001297
25. Sales KJ, Katz AA, Millar RP, Jabbour HN. Seminal plasma activates cyclooxygenase-2 and prostaglandin E2 receptor expression and signalling in cervical adenocarcinoma cells. Mol Hum Reprod. (2002) 8:1065-70. doi: 10.1093/molehr/8.12.1065

26. Sutherland JR, Sales KJ, Jabbour HN, Katz AA. Seminal plasma enhances cervical adenocarcinoma cell proliferation and tumour growth in vivo. PLoS ONE (2012) 7:e33848. doi: 10.1371/journal.pone.0033848

27. Jeremias J, David SS, Toth M, Witkin SS. Induction of messenger RNA for the $70 \mathrm{kDa}$ heat shock protein in HeLa cells and the human endocervix following exposure to semen: implications for antisperm antibody production and susceptibility to sexually transmitted infections. Hum Reprod. (1997) 12:1915-9. doi: 10.1093/humrep/12.9.1915

28. Aitken RJ, Baker MA. Causes and consequences of apoptosis in spermatozoa; contributions to infertility and impacts on development. Int J Dev Biol. (2013) 57:265-72. doi: 10.1387/ijdb.130146ja

29. Landry JJ, Pyl PT, Rausch T, Zichner T, Tekkedil MM, Stutz AM, et al. The genomic and transcriptomic landscape of a HeLa cell line. G3 (Bethesda) (2013) 3:1213-24. doi: 10.1534/g3.113.005777

30. Merbah M, Introini A, Fitzgerald W, Grivel JC, Lisco A, Vanpouille $\mathrm{C}$, et al. Cervico-vaginal tissue ex vivo as a model to study early events in HIV-1 infection. Am J Reprod Immunol. (2011) 65:268-78. doi: 10.1111/j.1600-0897.2010.00967.x

31. Bhise NS, Ribas J, Manoharan V, Zhang YS, Polini A, Massa S, et al. Organ-ona-chip platforms for studying drug delivery systems. J Control Release. (2014) 190:82-93. doi: 10.1016/j.jconrel.2014.05.004

32. von Wolff M, Nowak O, Pinheiro RM, Strowitzki T. Seminal plasmaimmunomodulatory potential in men with normal and abnormal sperm count. Eur J Obstet Gynecol Reprod Biol. (2007) 134:73-8. doi: 10.1016/j.ejogrb.2007.01.009

Conflict of Interest Statement: The authors declare that the research was conducted in the absence of any commercial or financial relationships that could be construed as a potential conflict of interest.

Copyright (C) 2018 Rametse, Adefuye, Olivier, Curry, Gamieldien, Burgers, Lewis, Williamson, Katz and Passmore. This is an open-access article distributed under the terms of the Creative Commons Attribution License (CC BY). The use, distribution or reproduction in other forums is permitted, provided the original author(s) and the copyright owner(s) are credited and that the original publication in this journal is cited, in accordance with accepted academic practice. No use, distribution or reproduction is permitted which does not comply with these terms. 